\title{
GEGURITAN NALADAMAYANTI \\ ANALISIS PENOKOHAN
}

\author{
Oleh \\ I Wayan Sugita, M.Si.
}

\begin{abstract}
ABSTRAK
Tokoh utama (protagonis) diduduki oleh Raja Nala, sedangkan tokoh antagonis diperankan oleh Dewi Damayanti. Penokohan Raja Nala mengalami perubahan atau dilukiskan secara dinamis, secara fisik, semula tampan, kemudian berubah menjadi cacat, kurus, dan kotor, akhirnya kembali tampan sesuai dengan rangkaian peristiwa yang dialaminya. Raja Nala secara psikologis diceritakan berwatak jujur, adil, bijaksana, dan setia. Perilaku Raja Nala didorong oleh faktor kekuasaan dan seks, yakni ia berusaha merebut kembali cinta kasihnya dengan Dewi Damayanti yang telah ditinggalkannya di tengah hutan. Beliau mengalami kesedihan dan kesengsaraan karena tidak mampu mengendalikan pikirannya dan mengingkari kesetiaannya kepada Dewi Damayanti. Pernikahan dengan Raja Nala merupakan pertemuan jodoh yang serasi, harmonis, dan sangat setia. Kesetiaan Dewi Damayanti diuji oleh Catur Dewata.
\end{abstract}

\section{Kata Kunci: Penokohan}

\section{ABSTRACT}

The main character (protagonist) was occupied by King Nala, while the antagonist played by Dewi Damayanti. Characterizations of King Nala changes or described in dimanis, physically, originally handsome, then turned into a deformed, thin and dirty, finally returned handsome accordance with a series of events that happened. King Nala psychologically told tempered honest, fair, thoughtful, and faithful. King Nala behavior is driven by factors of power and sex, which he tried to reclaim his love by Dewi Damayanti who have been left behind in the woods. He suffered grief and sorrow for not being able to control his mind and whose loyalty to Dewi Damayanti. Marriage to King Nala is meeting a mate matching, harmonious, and very loyal. Dewi Damayanti loyalty tested by Chess Gods.

\section{Keywords: Characterizations}

\section{PENDAHULUAN}

Geguritan Naladamayanti merupakan salah satu bentuk sastra Bali tradisional yang digubah oleh Ida Putu Maron, di Desa Ubud, Gianyar pada tahun 1958. Geguritan itu mengandung nilai budaya yangluhur clan menjadi sumber informasi dari suatu dunia berbudaya dantradisi peradaban pada masa lampau karena cerita itu bersumber padaepos Mahabarata. Gubahan itu sangat indah, mengesankan, dan mengandung ajaran kesetiaan sejati yang penyampaiannya sangat halus, berguna baik bagi orang tua maupun orang anda dalam kehidupan sehari-hari.

Geguritan Naladamayanti mengandung santapan rohani yang tinggi dan betulbetul merefleksikan persoalan manusia sebagai hasilrenungan pengarang terhadap 
kompleksitas kehidupan dengan alam sekelilingnya. Di dalam geguritan itu tampak pandangan, pendirian, dan pengalaman pengarang sehingga karya sastra itu memberikan nilai lebih bagi pembacanya terutama sikap etika, moral, dan religi. Kekuatan geguritan itu antaralain, terlihat pada keberhasilan pengarang memberikan kekhasan dalam penokohan, seperti nampak pada kemandirian dan ketinggian martabat tokoh-tokoh cerita, terutama tokoh wanitanya; Damayanti, dan keberhasilan melukiskan latar serta suasananya yang memang dituntut oleh kejadian dalam cerita. Kekuatan-kekuatan itu dapat menutupi hambatan psikologis pembaca berupa ketidakingintahuan atau kebosanan akan jalan cerita karena geguritan itu sebagai cerita rakyat mereka sudah sangat mengenalnya. Oleh karena itu, geguritan tersebut perlu diteliti sehingga mampu memberikan masukan bagi pembangunan moral manusia Indonesia seutuhnya dan tidak kehilangan jejak dengan peradaban masa lampau.

Sepanjang diketahui penelitian terhadap Geguritan Nala Damayanti sudah pernah dilakukan, antara lain, oleh (1) Cokorda Istri Muryati, (1984) Geguritan Nala Damayanti : Alih Bahasa, kajian itu terbatas pada masalah alih bahasa dari bahasa Bali ke bahasa Indonesia. (2) I Wayan Sumanjaya (1997) "Kajian Intertekstualitas Nala Damayanti dengan kisah Damayanti”, bahwa geguritan itu bersumber pada epos Mahabarata bagian Wanaparwa, perihal perilaku istri yang sangat setia kepada suami, kisah putri Damayanti yang menikah dengan Raja Nala yang dimodifikasikan oleh pengarang sehingga cerita itu sangat indah dan enak dibaca. (3) I Made sudiarga (1998/1999) "Geguritan Nara Damayanti : Analisis Tema, Amanat, dan nilai Budaya", bahwa kesetiaan seorang istri kepada suami merupakan tema geguritan itu dan karya sastra itu sangat bermanfaat bagi masyarakat karena mengandung nilai budaya yang luhur, kesetiaan merupakan nilai budaya yang paling menonjol dalam geguritan itu. (4) Grup STSI Denpasar telah memvisualisasikan cerita Nala Damayanti dalam rangka memeriahkan pesta Kesenian Bali tahun 1997, pementasan itu disiarkan pura oleh RRI dan TVRI stasiun Denpasar.

Penelitian di atas belum ada yang menelaah Geguritan Nala Damayanti dari aspek sastra secara struktural. Oleh karena itu, penelitian lanjutan terhadap geguritan itu perlu dilakukan agar pemasyarakatan pemahaman, penghayatan, dan pengamalan nilai budaya yang luhur yang terdapat di dalam cerita itu dapat diungkapkan dan dijadikan pedoman dan penangkal pengaruh budaya luar yang kurang menguntungkan.

Upaya pembinaan dan pengembangan sastra Bali tradisional dengan segala aspeknya merupakan suatu upaya untuk dapat menggugah kecintaan pada karya sastra itu serta dapat mengaktualisasikan nilai budaya yang terdapat di dalamnya sehingga bermakna bagi kehidupan bemasyarakat. Hal ini mengandung arti adanya usaha secara terus- menerus untuk, mengapresiasi dan menawarkan tafsir baru tanpa meninggalkan akar budaya sehingga mampu mengisi jiwa baru untuk menjawab tantangan zamandi masa depan, sehubungan dengan usaha itu, maka Geguritan Nala Damayanti diteliti dengan masalah bagaimanakah penokohan geguritan itu?

Penelitian ini bertujuan untuk melestarikan, membina, mengembangkan sastra Bali tradisional, memberikan sumbangan berupa bahan pelajaran dalam bidang pengajaran sastra Bali dan pendidikan budi pekerti bagi generasi muda, serta memperkaya khasanah penelitian sastra Bali tradisional. Di samping itu juga bertujuan untuk mendeskripsikan Penokohan geguritan Nala Damayanti. Deskripsi itu dapat dijadikan pengisi dan pelengkap dalam menumbuh kembangkan minat baca masyarakat terhadap karya sastra Bali yang masih dirasakan sangat terbatas. 


\section{LANDASAN TEORI}

Penelitian aspek sastra Geguritan Nala Damayanti menerapkan landasan teori struktural dengan dasar analisis mengungkapkan hakikat keberadaan karya sastra itu. Konsep ini berangkat dari pemikiran bahwa makna suatu teks (sastra) hanya dapat dipahami dan ditentukan oleh kualitas hubungan antar unsurnya, masingmasing unsur tersebut menduduki fungsi dalam rangka menentukan makna unsur yang lainnya. Konsep itu berarti bahwa struktur tersebut bersifat dinamis (Hawkes, 1977:16).

Prinsip analisis struktur bertujuan membongkar dan memaparkan secermat, seteliti, sedetail, dan sedalam mungkin keterkaitan dan keterjalinan semua anasir dan aspek karya sastra yang bersama-sama menghasilkan makna menyeluruh (Teeuw, 1984:133).

Menurut Panuti Sudjiman (1988:16-19) bahwa tokoh adalah individu rekaan yang mengalami peristiwa atau berkelakuan di dalam berbagai peristiwa cerita. Kriteria yang digunakan untuk menentukan tokoh utama bukan frekuensi kemunculan tokoh itu di dalam cerita, melainkan intensitas keterlibatan tokoh di dalam peristiwa-peristiwa yang membangun cerita. Tokoh yang merupakan penentang utama dari protagonist disebut antagonis atau tokoh lawan. Di dalam sastra tradisional biasanya pertentangan di antara protagonist dan antagonis jelas sekali. Protagonis mewakili tokoh yang baik dan terpuji karena itu biasanya menarik simpati pembaca sedangkan antagonis mewakili pihak yang salah atau jahat.

Tokoh-tokoh cerita itu rekaan pengarang, hanya pengaranglah yang 'mengenal' mereka, maka tokoh-tokoh itu perlu digambarkan ciri-ciri lahir, sifat, dan sikap hatinya agar wataknya juga dikenal oleh pembaca. Watak merupakan kualitas tokoh nalar, dan jiwanya yang membedakannya dengan tokoh lain. Penyajian watak tokoh dan penciptaan citra tokoh disebut penokohan (Sutjiman, 1988:23).
Ada beberapa metode penyajian watak tokoh atau metode penokohan, masingmasing dengan kelebihan dan kekurangannya. Adakalanya pengarang melalui penceritanya mengisahkan sifat-sifat tokoh, hasrat, pikiran dan perasaannya, kadang-kadang dengan menyelipkan kilatan atau komentar, pernyataan setuju tidaknya akan sifat-sifat tokoh itu, metode ini disebut metode analisis. Metode yang kedua ialah metode dramatik, cakapan, atau lakuan tokoh demikian pula pikiran tokoh yang dipaparkan oleh pengarang dapat menyiratkan sifat wataknya. Ketiga metode kontekstual, dengan metode ini, watak tokoh dapat disimpulkan dari bahasa yang digunakan pengarang di dalam mengacu kepada tokoh (Sudjiman, 1988: 25-26).

\section{METODE DAN TEKNIK}

Dalam menganalisis Geguritan Nala Damayanti menggunakan metode Hermeneutika (pemahaman), sebuah teks hanya dapat bermakna apabila teks itu dibaca atau kualitas sebuah naskah dan teks hanya dapat ditentukan melalui pembacanya. Sementara itu, pembacaan akan memungkinkan diperkenalkannya. Sementara itu, pembacaan akan memungkinkan diperkenalkannya interprerasi, pembacaan itu dilakukan secara struktural, yakni bergerak secara bolak-balik dari bagian kekeseluruhan dan kembali lagi ke bagian dan seterusnya dengan mempertimbangkan relasi antar unsur atau bagian-bagiannya. Berdasarkan hasil pembacaan itu, lalu diadakan interpretasi guna dapat merekuperasimakna.

Dalam praktik interpretasi itu dimulai dari interpretasi menyeluruhyang bersifat sementara untuk kemudian menafsirkan bagian-bagian. Penafsiran bagian-bagian itu diupayakan dapat memperbaiki pemahaman keseluruhan karya, dan seterusnya sehingga tercapai taraf penafsiran yang mencerminkan integrasi makna total dan makan bagian yang optimal (Teeuw, 1984:124-125). Dalam modal 
pembacaan semacam ini, berbagai tataran dalam Geguritan Nala Damayanti seperti lirik, bait, dan satuan naratif dipandang sebagai rangkaian satuan informasi berturut-turut dan sebagai satuan semantik.

Sementara itu, teknik yang digunakan adalah pencatatan dengan tujuan untuk menghindari data yang terlupakan akibat keterbatasan kemampuan daya ingat peneliti. Data yang telah dikutip dicatat dalam sebuah kartu dengan ukuran panjang $20 \mathrm{~cm}$ dan lebar $10 \mathrm{~cm}$.

\section{SUMBER DATA}

Naskah Geguritan Nala Damayanti koleksi Perpustakaan Lontar Fakultas Sastra Universitas Udayana Denpasar sudah dialih aksarakan dari huruf Bali ke huruf latin dan dialih bahasakan dari bahasa Bali ke bahasa Indonesia oleh Cokorda Istri Mulyati, tahun 1984. Dalam penelitian ini, naskah tersebut di atas dijadikan sumber data penelitian berdasarkan beberapa pertimbangan, antara lain (1) naskah itu sudah diterbitkan dan didistribusikan secara nasional; (2) ciriciri keaslian dan konvensi budaya tetap dipertahankan; dan (3) dari pembaca pertama kali, ternyata teks itu mengandung segi-segi positif untuk penelitian struktur, atas dasar pendapat sementara, teks menyajikan cerita yang lengkap dengan jalan cerita yang baik dan lancar.

\section{GEGURITAN NALA DAMAYANTI: ANALISIS PENOKOHAN SINOPSIS}

Raja Nala mengurus Si Swacita agar menyampaikan isi hatinya kepada Dewi Damayanti di Widarba. Dewi Damayanti menerima utusan itu dengan senang hati dan membalas cinta kasih Raja Nala dengan perantaraan si Swacita pula. Dewi Damayanti sejak jatuh cinta kepada Raja Nala selalu gelisah, tidak enak makan, dan badannya lemah. Raja Bima memahami perubahan perilaku putrinya itu, lalu memutuskan melaksanakan sayembara memilih suami bagi Dewi Damayanti.

Raja Nala dalam perjalanan ke Widarba bertemu dengan Catur Dewata yang juga akan mengikuti sayembara. catur Dewata itu menguji kesetiaan Raja Nala dengan cara mengutus Raja Nala agar menyampaikan pesan supaya dalam sayembara Dewi Damayanti memilih Catur Dewata sebagai suaminya. Dewi Damayanti pun diuji kesetiaannya kepada Raja Nala dengan cara catur Dewata menjelma menjadi Raja Nala sehingga dalam sayembara itu ada lima orang peserta yang wajahnya sama dengan Raja Nala. Raja Nala dan Dewi Damayanti berhasil memecahkan ujian itu berkat kesetiaan mereka yang tulus, lalu pernikahanpun dilaksanakan.

Raja Nala ditantang berjudi oleh Raja Puskara dengan mempertaruhkan kerajaan dan segenap isinya, Raja yang kalah harus menyerahkan seluruh taruhannya kemudian meninggalkan kerajaan. Raja Nala kalah dalam perjudian itu lalu beliau mengembara ke tengah hutan bersama permaisurinya.

Raja Nala memotong selimut Dewi Damayanti pada waktu tidur di bawah pohon, kemudian meninggalkannya seorang diri. Dewi Damayanti berusaha keras mencari suaminya dengan melalui berbagai rintangan di tengah hutan hingga sampai di Kerajaan cedi dan widarba. Raja Bima, ayah Dewi Damayanti, akan melaksanakan sayembara untuk memilih suami yang kedua kalinya bagi Dewi Damayanti dengan mengutus Sang Sudewa mengundang Raja Retuparna di Ayodia, utusan itu menyanyikan lagu yang mengisahkan kesedihan dan kerinduan Dewi Damayanti kepada Raja Nala.

Raja Retuparna dan sang Bauka menghadiri sayembara itu, ditengah pertajalan beliau menukar kepandaian berjudi dengan kemahiran menunggang kuda kepada sang Bauka. Raja putri Damayanti memperhatikan tingkah laku sang Bauka dengan seksama dalam setiap pertemuan di Widarba. Dewi 
Damayanti yakin dengan sepenuh hati, bahwa sesungguhnya sang Bauka adalah penyamaran Raja Nala. Dalam pertemuan yang dihadiri oleh kerabat istana, sang Bauka menunjukkan jati dirinyadan kesetiaannya kepada Dewi Damayanti sehingga mereka dapat berkumpul kembali penuh keharuan dan kebahagiaan. Puncak kebahagiaan yang mereka nikmati setelah berhasil merebut kembali kerajaannya dari Raja Sri Puskara.

\section{PENOKOHAN}

Geguritan Nala Damayanti didukung oleh sejumlah tokoh cerita dengan perannya masing-masing dan berbagai peristiwa yang dialaminya sehingga terbentuklah sebuah cerita yang sangat menarik. Peran parapelaku cerita itu ditentukan berdasarkan rangkaian peristiwa yang membentuk alur cerita dan intensitas kehadiran tokoh dalam penceritaan serta keterlibatan tokoh yang satu dengan tokoh yang lainnya. Berdasarkan kriteria itu kedudukan tokoh cerita dapat dirunut sebagai berikut: (a) Prabu Nala menduduki posisi sebagai tokoh utama (protogonis),(b) Dewi Damayanti menduduki posisi sebagai tokoh lawan (antagonis)dari tokoh utama, dan (c) Raja Bima, Raja Sri Puskara, Raja Ratuparna,Catur Dewata, dan si Swacita berperan sebagai tokoh bawahan. Dalam

analisis ini tidak semua tokoh cerita dibahas tetapi dibatasi hanya perwatakan tokoh protagonis (Raja Nala) dan tokoh antagonis (Dewi Damayanti), sedangkan tokoh bawahan yang lainnya akan disinggung sepintas karena pembahasan tokoh bawahan itu secara tersirat telah disinggung dalam pembicaraan tokoh protagonis dan tokoh antagonisdi atas.

Raja Nala secara fisik diceritakan sebagai raja muda yang ketampanannya terkenal keseluruh dunia. Setiap orang terpesona dan jatuh cinta akan ketampanan sang raja. Perkembangan fisiknya menunjukkan tandatanda yangkurang baik karena ditimpa berbagai penderitaan dan rintangan yang sangat berat. Ketampanannya sirna, badannya berkeringat, tubuhnya gemetar, kotor, dan matanya sendu ketika beliau mengikuti sayembara di Widarba memperebutkan Dewi Damayanti. Keadaan fisik Raja Nala itu berbeda dengan fisik Raja Nala sebagai penjelmaan dari Catur Dewata, fisiknya badannya tegap, bersih, dan matanya tidak berkedip. Perbedaan fisik itu dapat diketahui dalam kutipan berikut:

Sarira tan pawayangan, suku tan panginiak ksiti, nanging ringsamping nira, Prabhu Nala katon ngepil, paringate membah mijil, maka raga kaput ebuk, pangaksian idane ocak, gubahan sekaren kaksi, sami layu, Prabhu Nala semu wiring (GND, 1984:68).

\section{Terjemahan:}

Badannya tidak ada bayang-bayangnya, kakinya tidak menginjak bumi, tetapi disebelahnya, tampak Prabu Nala diam, keringatkan mengalir deras, sekujur tubuhnya terbungkus dengan debu, matanya selalu berkedip, bunganya kelihatan semua, seluruhnya layu, Prabu Nala wajahnya sangat kesal (GND, 1984:68).

FisikRaja Nala semakin buruk ketika beliau mengembara di tengah hutan yang hanya makan buah-buahan dan umbi-umbian sehingga badannya kurus, kotor, dan tidak sehat. Wajahnya cacat setelah digigit oleh Si Raja Ular sehingga sulit dikenali lagi, perubahan wajah itu menyebabkan beliau mengganti nama menjadi siBauka sebagai sais Raja Retu parna. Fungsi perubahan wajah dan penyamaran ini untuk menghindari kejaran atau penangkapan yang dilakukan oleh Raja Sri Puskara. Raja Nala yang wajahnya cacat akan normal lagi dengan menyatukan pikiran dan mengenakan selimut yang diberikan oleh si Raja Ular. Dengan selimut itu Raja Nala mempunyai keajaiban fisik seperti tampak pada kutipan berikut:

Yaning Bauka mamarga, nglintang kuri andap alit, tan ipun ngaedang sikian, nging korine mawuh inggih, taler yang ring rurung sempit, dados linggah rurungwai, yan ipun nglintang irika. 
Ring saksana wadah ika, madaging toya pramangkin, malih yangsagegeman padang, ne sinarin matanai, mandados puun gelis, limannya kaugang ratu, ring irika jroninggenia, nanging tan gesengyuakti, jaba nika, wenten malih sane tawah (GND. 1984:161-162).

Terjemahan :

Bila sang Bauka berjalan, melewati pintu yang rendah dan sempit, dia tidak membungkukkan dirinya, tetapi pintu itu yang bertambah tinggi, demikian pula bila berjalan di jalan yang sempit, jalan itu seketika menjadi lebar, bila dia melintasi jalan itu. Seketika tempat itu, berisi air dalam sekejap mata, lagi pula kalau segenggam rumput, yang disinari mentari, terbakar seketika. tangannya dimasukkan tuanku, ke sana ke dalam api, tetapi sungguh-sunsguh tak terbakar, selain itu, banyak lagi yang ajaib (GND, 1984:161162).

Dalam kutipan di atas tampak bahwa Raja Nala secara fisik mempunyai keajaiban seperti badannya tidak kebesaran bila memasuki ruangan yang kecil, kepalanya tidak tersandung bila memasuki ruangan yang rendah, dan tangannya tidak terbakar bila dimasukkan ke dalam bara api. Keajaiban itu berkat anugrah Raja ular yang telah dibebaskan dari kutukan Sang Mahayati.

Raja Nala secara psikologis diceritakan sebagai raja yang memerintah dengan adil, jujur, dan bijaksana serta berwibawa. Di samping itu beliaujuga mengalami kegelisahan dan kesedihan ketika kesetiaannya kepada Dewi Damayanti diuji oleh Catur Dewata. Kegelisahan itu muncul karena beliau takut pula melanggar perintah para dewata yang sangat dihormatinya. Dalam memecahkan masalah kebimbangan atau keragu-raguan batin itu, Raja Nala melaksanakan perintah catur Dewata yang dilandasi oleh sikap setia, hormat, dan tulus ikhlas. Raja Nala menghadap kepada Dewi Damayanti dengan perasaan sedih dan kepalanya sakit (pusing) karena ia datang hanya sebagai utusan Catur Dewata
(Dewa Indra, Dewa Agni, Dewa Baruna, dan Dewa Yama) yang menyarankan agar Dewi Damayanti menjatuhkan pilihannya hanya kepada Dewa Indra sebagai suaminya. Dewi Damayanti menolak pesan itu, ia tetap pada pendiriannya hanya akan memilih Raja Nala sehingga sang raja sangat gembirahatinya setelah mendapat kepastian itu. Raja Nala bersumpah kepada Dewi Damayanti bahwa ia tetap setia sehidup semati baik dalam suka maupun duka, sumpah itu diucapkan dalam prosesi pernikahan yang disaksikan oleh catur Dewata, para raja, dan segenap undangan yang hadir dalam pesta pernikahan itu. Sumpah setia Raja Nala kepada Dewi Damayangi diceritakan dalam kutipan berikut.

Prabhu nala saha sumpah, ring sang Dewi Damayanti, sanggup susatia masetma, urip tan pacang ngaro pawestri, duh ratu Bhatara catur, sansyaning nggih atur tityang, yang prade mresa ring janji, ledang ratu dikelang dosa ring titya (GND, 1984:71).

\section{Terjemahan :}

Prabu Nala bersumpah, kepada Dewi Damayanti, sanggup setia beristri, selama hidupnya tidak akan beristri dua orang ya tuan hamba Catur Dewata, saksikanlah sumpah hamba, apabila hamba ingkar janji, semoga sudi Tuan hamba melibatgandakan dosa pada hamba (GND, 1984:71).

Raja Nala melanggar sumpah kesetiaannya kepada Dewi Damayanti karena jiwanya telah diracuni oleh si Kala dan si Dwapara dengan kegemaran berjudi. Perjudian itu didorong oleh faktor kekuasaan yakni Raja Nala dan Raja Sri Puskara mempertaruhkan kerajaan masing-masing dalam meja perjudian. Kekalahan Raja Nala dalam perjudian itu mengakibatkan keadaan psikisnya labil sedih, marah, resah, dan tidak mau menerima nasihat orang lain termasuk nasihat permaisurinya. Super ego Raja Nala tersebut mengakibatkan ia terjerumus ke lembah kesengsaraan dan hidup dalam pengembaraan, puncak egoisme Raja Nala tampak pada ketidak mampuannya 
mengendalikan pikirannya sehingga tega meninggalkan istrinya seorang diri di tengah hutan. Raja Nala melanggar sumpah setia kepada Dewi Damayanti diceritakan dalam kutipan berikut:

Majalaran antuk pedang, ne kepanggih ika tuni, muli ida prabhuNala, nderes wastran da sang putri, ne atenga id angangge, saparon ida sang ayu, irika raris mamarga, ninggalin ida Putri, ngantun-antun, margine saking pondokan (GND, 1984:103-104)

Terjemahan :

Bersenjatakan. Dengan sebelah pedang, yang telah dilihatnya tadi, kemudian baginda Raja Nala, memotong kain selimut Raja Putri Damayanti, setengah bagian beliau yang mengenakannya, setengah bagian lagi dipakai oleh Dewi Damayanti, kemudian beliau berjalan meninggalkan Putri Damayanti, kemudian beliau berjalan meninggalkan Putri Damayanti, perlahan-lahan sekali, langkahnya dari pemondokan itu (GND, 1984:103-104).

Sikap suka berjudi dan melanggar sumpah kesetiaan merupakan sisi negatif untuk Raja Nala. Di samping itu, beliau mempunyai sifat yang positif seperti suka menolong dan tekun belajar. Kedua sifat positif Raja Nala itu merupakan suatu proses inisiasi atau pematangan jiwa dan kemampuan mental spiritual Raja Nala yang dipersiapkan untuk merebut kembali permaisuri dan kerajaannya yang telah lepas dari genggamannya. Proses pematangan jiwa itu, pertama dilakukan dengan menyamar sebagai sais kereta kuda bertujuan untuk menghindari pengejaran Raja Sri Puskara dan membinasakan pengaruh jahat si Kali dan si Dwapara terhadap Raja Nala. Kedua, Raja Nala menukar kemahiran menunggang kuda dengan kemahiran berjudi kepada Raja Retuparna dengan tujuan untuk merebut kembali kerajaannya dari tangan Raja Sri Puskara. Ketekunan Raja Nala mempelajari ilmu berjudi diceritakan dalam kutipan berikut:
Sang Retuparna mawuwus, kaweruh mangitung puniki, nunggil ring kaweruh pajudian, ne kadrewe ban nireki, yan kita suba mangajah, kaweruh mangoreg aswaji.

Nira maweh weruh judiki, waluya pangentos, neki, muput sida kadi ika, ri sampun sang Nalapati, menerima kaweruh punika, kali dusta musna gelis (GND, 1984:150).

Terjemahan:

Raja Retuparna bersabda, kepandaian menghitung ini sama dengan keahlian berjudi, yang aku miliki ini, kalau kamu sudah belajar, pengetahuan tentang menunggang kuda raja.

Aku memberikan ilmu judiku ini, ini sebagai penggantinya, setelah selesai hal itu, sesudah Raja Nala menerima pengetahuan itu, si Kali jahat cepat musnah (GND, 1984:150).

Peningkatan kemampuan Raja Nala seperti tampak pada kutipandi atas, secara psikologis merupakan dorongan faktor kekuasaan dan faktor seks karena dalam perjalanan hidupnya pernah kehilangan kerajaan dan permaisuri. Raja Nala berhasil merebut kembali kedua harta yang tak ternilai harganya itu sehingga beliau menikmati puncak keemasan dalam pemerintahan di Nisada

Raja Nala secara sosiologis diceritakan seorang raja yang memerintah di Kerajaan Nisada. Hubungan kekerabatan antara Raja Nala dan kakaknya, Raja Sri Puskara, tidak selamanya berlangsung harmonis karena pengaruh si Dwapara dan si Kali yang mengadu domba kedua raja itu dalam perjudian. Kekurangharmonisan itu disebabkan oleh tindakan balas dendam si Kala dan si Dwapara yang kalah dalam sayembara memperebutkan Dewi Damayanti. Tindakan balas dendam itu mengakibatkan Raja Nala kehilangan kerajaan dan mengembara selama dua belas tahun. Setelah selesai menjalani masa pembuangan, Raja Nala berhasil merebut kembali kerajaan Nisada, sebagian kerajaan itu dikembalikan lagi kepada kakaknya, Raja Sri Puskara, dan beliau tidak menghukum Raja Sri Puskara karena didorong oleh keinginan untuk 
mempertahankan keutuhan keluarga besar yang secara geneologis berasal dari satu darah keturunan Raja Nisada.

Percintaan Raja Nala dengan Dewi Damayanti diuji oleh Catur Dewata karena percintaan itu melalui perantaraan seekor burung SiSwacita sehingga Raja Nala tidak dibenarkan melamar Dewi Damayanti dilandasi kesetiaan yang sejati (sadampati) sehingga Catur Dewata merestui pernikahan itu dengan menganugrahkan dua orang putra dan kesaktian yang dapat mengalahkan berbagai kejahatan yang menguncang keharmonisan kehidupan rumah tangga dan kejayaan Kerajaan Nisada. Pernikahan Raja Nala dengan Dewi Damayanti merupakan pertemuan jodoh yang serasi, tampan, cantik, keturunan raja dan dihormati oleh segenap rakyatnya. Keserasian pernikahan itu diceritakan dalam kutipan berikut.

Sampun tutug pawarangan, perabian ida kalih, sang putri lawangsang putra, wah kayogya anyat mangkin, ne kakardining sangkalih, keh anak sami menyumbung, Damayanti lan sang Nala,wantah mula adung yukti, Damayanti, hayu luwih nindiyang sarat.

Sang Nala bagus tan pira, kalokang rat sri bhupati, Damayanti putring raja, Nala masih ratu luwih, lantur pakraman sang kalih,sih gumasih tut adulur, kayun trepti budi kreta, putri weruhsubakting laki, laki waruh sih, ida len istrinia (GND, 1984 :74-75).

Terjemahan:

Setelah selesai upacara perkawinan, pernikahan beliau berdua, Dewi Damayanti dengan Raja Nala, sekarang menempuh hidup baru, yang mereka berdua bina, banyak orang memuja-muji, Dewi Damayanti dan Raja Nala sungguh serasi, Dewi Damayanti, sangat cantik dan terpuji di seluruh dunia.

Raja Nala sangat tampan, tak terkira, terkenal di dunia baginda raja, Damayanti putri raja, Prabu Nala juga raja yang pandai, berlanjut pernikahan mereka berdua, saling mengasihi dan menyayangi, sejahtera aman dan tentram, Raja Putri tahu berbhakti kepada suami, suami tahu cinta kasih, beliau bersama istrinya.(GND. 1984 :73-74).

Dalam kutipan diatas tampak bahwa Raja Nala dan Dewi Damayanti setia dan saling mencintai dan menyayangi dalam membina keharmonisan rumah tangganya. Keharmonisan itu tidak berlangsung lama karena Raja Nala mengkhianati kesetiaan kepada Dewi Damayanti sebagai akibat dari tindakan balas dendam Si Kali dan Si Dwapara atas kekalahannya dalam sayembara. Walaupun Raja Nala telah meninggalkan istrinya tetapi beliau tetap mencintai dan berharap suatu hari mereka dapat bersatu kembali seperti sedia kala. Raja Nala berhasil mencapai harapan-harapan itu berkat bantuan Raja Ular dan Raja Retuparna.

Dewi Damayanti secara fisik diceritakan, sebagai seorang tokoh wanita yang sangat cantik. Kecantikan Dewi Damayanti dapat diketahui dari percakapan antara Raja Nala dan Si Swacita serta perbincangan atau kekaguman para peserta sayembara. Kecantikan Dewi Damayanti diceritakan oleh si Swacita seperti tampak pada kutipan berikut:

Nawiratudurungwikan, ring Raja Bima pinuji, nateng Widarba negara, madrewe putri ayu mulus, rauh mangkin dereng krama, tui tan kidik, prabu truna rauh nglamar.

Damayanti sajnya nira, sapunika atur sang paksi, ne ngedeng kayun sang nata, tur pamuput dadi tumbuh, meled kayune marabian, punang paksi, sumanggup dados jalaran (GND, 1984:33-34)

Terjemahan:

Barang kali paduka tuanku belum mengetahui, Raja Bima tang terkenal, raja dari Kerajaan Widarba, mempunyai seorang putri yang cantik jelita, sampai sekarang belum menikah, sungguh tidak sedikit, raja muda datang melamar.

Dewi Damayanti nama beliau, demikianlah kata si Swacita, yang membuat menarik hati sang raja, dan akhirnya timbul, keinginan sang 
raja menikahi, burung Swacita itu sanggup menjadi perantara (GND, 1984:33-34).

Dewi Damayanti mengalami perubahan fisik yang kurang menggembirakan ketika jatuh cinta kepada Raja Nala, karena tidak ada nafsu makan dan minum sehingga kondisi badannya lemah, wajahnya pucat, bibirnya kembang, cahaya mukanya suram, dan tubuhnya kurus kering.

Misnan wadanan sang Diah, muuhmuuh acum lesit, raga etuhlambe kembang, dadoyane mangan nginum, risaksana dadi tuna, sendik niki, gelis uning Raja Bima (GND, 1984:40).

Terjemahan :

Sirnalah cahaya muka Diah Damayanti, semakin pucat pasi, badannya kurus kering, bibirnya kembang, nafsu makan dan minum, seketika berkurang, tentang perubahan ini, segera diketahui oleh Raja Bima (GND, 1984:40).

Keadaan fisik Dewi Damayanti semakin memprihatinkan ketika mengembara di tengah hutan, wajahnya aneh dan menakutkan, badannya kotor, kurus, dan menjijikkan sehingga diusir dan dihina oleh setiap orang yang didekatinya. Sepanjang perjalanan yang melelahkan itu, ia hanya makan buah-buahan yang diperoleh ditengah hutan. Setengah badannya tidak terbalut dengan kain karena sebagian kain yang dikenakannya telah dipotong oleh Raja Nala ketika tertidur lelap di tengah hutan.

Dewi Damayanti secara sosiologis diceritakan ibarat Srikandi dalam pewayangan yangberanimajukemedan perangketika situasi menuntutnya. Dewi Damayanti pun berani maju ke medan perang asmara menentang Dewa Indra yang berubah wujud menjadi Raja Nala, karena hati kecil kewanitaannya tidak dapat menerima lelaki siluman itu, walaupun penentangnya ini menimbulkan ketidak harmonisan lingkungannya.

Dewi Damayanti dilukiskan sebagai tokoh wanita garda depan,tokoh pendobrak, tokoh yang penuh percaya diri dan berani menentang arus demi keyakinannya. Pada zamannya kalau seorang wanita akan diangkat menjadi selir seorang penguasa ibarat ia mendapat anugrah luar biasa. Pandangan ini tidak pernah terlintas dalam benak Dewi Damayanti. Ia benar-benar tokoh yang mandiri.

Kukuh ring pemineh ngeraga, tan suci aserah, ring pamutus anaklian, yadin dewa sinung lungguh, nging dewa tan kurang naya, mileg kapti, Damayanti ring paseban (GND, 1984:60).

\section{Terjemahan:}

tetap teguh pada pendiriannya, tidak mudah menyerah, pada keputusan orang lain, walaupun kehendak para dewata, tetapi paradewa tidak kehabisan tipu daya, mengikuti sayembara, memperebutkan Dewi Damayanti di Paseban (GND, 1984:60).

Keteguhan pendirian Dewi Damayanti seperti tampak pada kutipan di atas, bagi pembaca pria GND menyampaikan semacam otokritik akan sikap sekelompok pria yang suka mengeksploitasi, meremehkan, atau menekan kaum wanita. Bagi pembaca wanita, GND ini dapat menjadi penggugah, menjadi cambuk kesadaran mereka akan hak dan martabat mereka yang kadang-kadang terserobot oleh pria.

Dewi Damayanti dilukiskan sebagai seorang tokoh yang sangat setia, sabar, dan bijaksana. Kesetiaannya pada suaminya, merupakan landasan setiap gerak langkahnya dalam usaha mencapai kerukunan, keharmonisan, dan kebahagiaan lahir batin. Setia merupakan landasan perbuatan Dewi Damayanti kepada Raja Nala yang diwujudkan dalam sumpah patibrata sebagai lambang cinta sejati sehidup semati baik dalam suka maupun duka. Kesetiaan itu telah dipuji sebanyak tiga kali yakni: (a) catur Dewata menjelma menjadi Raja Nala sehingga dalam sayembara itu ada lima orang peserta wajahnya sama dengan Raja Nala, (b) Dewi Damayanti mengikuti pengembaraan Raja Nala dan (c) Dewi Damayanti tetap 
memilih Raja Nala yang telah berubah wujud sebagai seorang sais kuda, sebagai suaminya yang kedua. Kesetiaan seorang sais kuda, sebagai suaminya yang kedua. Kesetiaan Dewi Damayanti diceritakan dalam kutipan berikut.

Manuhara patibrata, wicaksana stiti bakti, tui tan wanten mangasorang, ring saluwaning buana agung, yadin sasoring akasa, luhur pritiwi, patut dadi kembang jagat (GND, 1984:8).

Terjemahan:

Penyabar sangat setia kepada suami, bijaksana bersujud dan berbhakti, sungguh tidak ada yang mengalahkannya, di atas dunia ini, maupun dibawah angkasa, di atas bumi, patut menjadi kusuma bangsa (GND, 1984:8).

Dewi Damayanti secara sosiologis diceritakan sebagai putri Raja Bima yang bertahta di Widarba. Dewi Damayanti menjalin cinta kasih dengan Raja Nala melalui perantaraan seekor burung, si Swecita, sehingga cinta itu diragukan oleh catur Dewata. Keempat dewa itu menguji kesetiaan Dewi Damayanti dengan menyamar sebagai Raja Nala yang juga mengikuti sayembara. Dewi berhasil lulus dari ujian itu sehingga catur Dewata merestui pernikahan Dewi Damayanti dengan Raja Nala menganugrahkan dua orang putra dari pernikahan itu. Kehidupan rumah tangga Dewi Damayanti mengalami kehancuran pada waktu mereka menjalani pembuangan di tengah hutan.Walaupun mengalami cobaan yang sangat berat, Dewi Damayanti tetap berusaha keras agar dapat bersatu kembali dengan suaminya. Berkat bantuan dari si pemburu, sang brahmana, putri Raja Cedi, dan sang Sudewa, akhirnya Dewi Damayanti dapat bersatu kembali dengan suaminya, Raja Nala, dan kedua orang putranya dalam suasana sukacita.

\section{SIMPULAN}

Geguritan Nala Damayanti didukung oleh para pelaku yang mempunyai peran masing-masing sehingga terbentuklah sebuah rangkaian cerita yang menarik. Tokoh utama (protagonis) diduduki oleh Raja Nala, sedangkan tokoh antagonis diperankan oleh Dewi Damayanti. Penokohan Raja Nala mengalami perubahan atau dilukiskan secara dinamis, secara fisik, semula tampan, kemudian berubah menjadi cacat, kurus, dan kotor, akhirnya kembali tampan sesuai dengan rangkaian peristiwa yang dialaminya.

Raja Nala secara psikologis diceritakan berwatak jujur, adil, bijaksana, dan setia. Perilaku Raja Nala didorong oleh faktor kekuasaan dan seks, yakni ia berusaha merebut kembali cinta kasihnya dengan Dewi Damayanti yang telah ditinggalkannya di tengah hutan. Beliau mengalami kesedihan dan kesengsaraan karena tidak mampu mengendalikan pikirannya dan mengingkari kesetiaannya kepada Dewi Damayanti.

Raja Nala secara sosiologis diceritakan sebagai salah seorang putra Raja Nisada. Beliau menikah dengan Dewi Damayanti, dari pernikahan itu melahirkan dua orang putra. dalam usahanya mempertahankan keutuhan keluarganya, dan merebut kembali kerajaannya, beliau mendapat bantuan dari Si Raja Ular, Raja Retuparna, sebaliknya beliau mengalami ujian dari Catur Dewata dan si Kali serta Si Dwapara. Penokohan Dewi Damayanti diceritakan sangat kompleks, artinya baik keadaan fisik dan psikologisnya mengalami perkembangan yang positif seperti kecantikannya semakin bersemi juga mengalami kemunduran, kecantikannya sirna, badannya kurus, dan pucat, maupun secara sosiologis ia melakukan kontak dan kerjasama dengan tokoh-tokoh cerita.

Dewi Damayanti adalah dalam memilih suami haruslah berdasarkan pilihan hati nurani yang luhur dan dilandasi kesetiaan sehingga keutuhan dan keharmonisan rumah tangga tetap kokoh.

Dewi Damayanti merupakan putri Raja Bima di Widarba. Pernikahan dengan Raja Nala merupakan pertemuan jodoh yang serasi, harmonis, dan sangat setia. Kesetiaan 
Dewi Damayanti diuji oleh Catur Dewata, sedangkan keutuhan rumah tangganya diganggu oleh si Kali dan si Dwapara. Untuk menjaga keutuhan dan keharmonisan rumah tangganya, ia dibantu oleh si Swacita, permaisuri Raja Cedi, dan Sang Sudewa.

\section{DAFTAR PUSTAKA}

Hawkes, Terence. 1977. Strukturalism and Semiotics. California: University of California Press

Mulyati, Cokorda Istri Sri. 1984. Geguritan Nala Damayanti: AlihAksaradan Alih Bahasa. Jakarta: Pusat Pembinaan dan Pengembangan Bahasa.

Sudiarga, I Made.1998/1999. “Geguritan Nala Damayanti: Analisis Tema, Amanat, dan Nilai Budaya”. Denpasar: Balai Bahasa.

Sudjiman, Panuti. 1988. Memahami Cerita Rekaan. Jakarta: Pustaka Jaya.

Sumanjaya, I Wayan. 1997. "Kajian Intertekstualitas Nala Damayanti dengan Kisah Damayanti". Denpasar: Fakultas Sastra UniversitasUdayana.

Teeuw, A. 1984. Sastra dan Ilmu Sastra Pengantar Teori Sastra. Jakarta: Pustaka Jaya. 